\title{
Towards sustainable wastewater treatment by using microbial fuel cells-centered technologies
} Cite this: Energy Environ. Sci., 2014, 7, 911

\begin{abstract}
Wen-Wei Li, ${ }^{a}$ Han-Qing $\mathrm{Yu}^{* a}$ and Zhen $\mathrm{He}^{\star \mathrm{b}}$
Microbial fuel cells (MFCs) have been conceived and intensively studied as a promising technology to achieve sustainable wastewater treatment. However, doubts and debates arose in recent years regarding the technical and economic viability of this technology on a larger scale and in a real-world applications. Hence, it is time to think about and examine how to recalibrate this technology's role in a future paradigm of sustainable wastewater treatment. In the past years, many good ideas/approaches have been proposed and investigated for MFC application, but information is scattered. Various review papers were published on MFC configuration, substrates, electrode materials, separators and microbiology but there is lack of critical thinking and systematic analysis of MFC application niche in wastewater treatment. To systematically formulate a strategy of (potentially) practical MFC application and provide information to guide MFC development, this perspective has critically examined and discussed the problems and challenges for developing MFC technology, and identified a possible application niche whereby MFCs can be rationally incorporated into the treatment process. We propose integration of MFCs with other treatment technologies to form an MFC-centered treatment scheme based on thoroughly analyzing the challenges and opportunities, and discuss future efforts to be made for realizing sustainable wastewater treatment.
\end{abstract}

Received 15th September 2013 Accepted 26th November 2013

DOI: 10.1039/c3ee43106a

www.rsc.org/ees

\section{Broader context}

Our society's expectations for wastewater treatment have evolved over time. While protecting aquatic environment and public health continues to be a paramount concern, the desire to recover clean water, energy and useful resources from wastewater is getting increasingly stronger today. This increased demand on wastewater treatment has stimulated intensive research for sustainable treatment technologies. Microbial fuel cell (MFC) has been regarded as a promising technology to serve this goal, but low power density, high cost and difficulty in reactor scaling-up severely limit its development and give rise to debates about its practical feasibility. Here, we provide critical rethinking about the challenges and opportunities of this technology, and propose a more promising avenue for MFC development-through integration with other enhanced treatment and resource recovery technologies for more sustainable wastewater treatment. The advantages of such an MFC-centered treatment system in terms of energy consumption, environmental footprint, operating stability and economics are analyzed, and an exemplary process flow is presented.

\section{Introduction}

The problems of fossil-fuel depletion, environmental pollution, water and other resource shortage are driving intensive efforts towards more sustainable treatment and utilization of wastewater. Indeed, while abating contamination continues to be an important task of wastewater treatment, sustainability is gradually becoming a pivotal criterion and driving force to its further advancement. Unfortunately, at the present stage wastewater treatment processes are generally energy intensive and require high investment and operating costs. During the treatment a considerable amount of greenhouse gases (GHGs), such as

${ }^{a}$ Department of Chemistry, University of Science \& Technology of China, Hefei, 230026, China. E-mail: hqyu@ustc.edu.cn; Fax: +86-551-63601592

${ }^{b}$ Department of Civil and Environmental Engineering, Virginia Polytechnic Institute and State University, Blacksburg, Virginia 24061, USA. E-mail: zhenhe@vt.edu carbon dioxide $\left(\mathrm{CO}_{2}\right)$ and nitrous oxide $\left(\mathrm{N}_{2} \mathrm{O}\right)$, and other volatile substances are released into the atmosphere, and in the meantime excess sludge is produced and needs further disposal. Moreover, many valuable resources such as phosphate $\left(\mathrm{PO}_{4}{ }^{3-}\right)$, ammonia $\left(\mathrm{NH}_{4}{ }^{+}\right)$and some metals contained in wastewater are not recovered. All these facts substantially lower process sustainability.

Nonetheless, wastewater treatment does have the potential to become a sustainable process if suitable technologies can be adopted. Today, society is increasingly aware that wastewater could be a valuable source of energy and resources rather than "waste"-an awareness that has led to a shift in our way of handling wastewater and stimulated the development of various energy-efficient and resource-recovering technologies. For example, anaerobic digestion (AD) processes enable efficient recovery of energy in the form of methane $\left(\mathrm{CH}_{4}\right)$ or $\mathrm{H}_{2}$ from wastewater to partially offset the energy consumption for 
treatment; struvite precipitation process can simultaneously recover phosphate and ammonia. Among these developments, microbial fuel cell (MFC) as an emerging technology is bringing new opportunities. ${ }^{1,2}$ Especially, MFC technology could be highly adaptable to a sustainable pattern of wastewater treatment for several reasons: (1) it enables direct recovery of electric energy and value-added products; (2) good effluent quality and low environmental footprint can be achieved because of effective combination of biological and electrochemical processes; and (3) it is inherently amenable to real-time monitoring and control, which benefits good operating stability.

However, practical application of MFC technology has not been realized, because of great challenges in cost, system development, and energy recovery. To find out whether the envisioned advantages of this technology can be ultimately achieved, we need to re-examine the challenges and feasibility of this technology, and to think about how to recalibrate the role of this technology in a future paradigm of sustainable wastewater treatment.

With a critical analysis of the opportunities and challenges of MFCs for wastewater treatment, this perspective aims to offer some useful information to address key issues such as whether we can possibly achieve sustainable operation of MFCs for wastewater treatment and how, and to stimulate more thinking and discussion of a possible application niche for MFC technology. An MFC-centered hybrid treatment system is proposed as an example of integrating MFCs and relevant technologies for improving treatment sustainability.

\section{How might MFC technology contribute to sustainable wastewater treatment: opportunities and challenges}

Sustainable wastewater treatment is a fascinating concept that promises to partially address the multiple challenges of energy shortage, resource depletion and environmental pollution. It is widely accepted that a sustainable treatment process should strive for: neural-energy operation, balanced investment and economic output, stable treatment performance, high effluent quality to meet water reclamation and reuse requirement, less resource consumption, a low environmental footprint, and good social equity. ${ }^{3,4}$ It is essentially difficult to simultaneously meet all these criteria with the existing technologies and/or single treatment technology. The MFC technology, although still at its infancy, might bring in new opportunities because of its many unique features (Fig. 1). To facilitate an in-depth analysis, social sustainability is not covered here.

\subsection{Energy balance}

It is estimated that municipal wastewater contains approximately 9.3 times more energy than currently needed for its treatment in a modern municipal wastewater treatment plant (WWTP). ${ }^{5}$ The value is even higher for carbohydrate-rich wastewaters such as those from food-processing and brewery

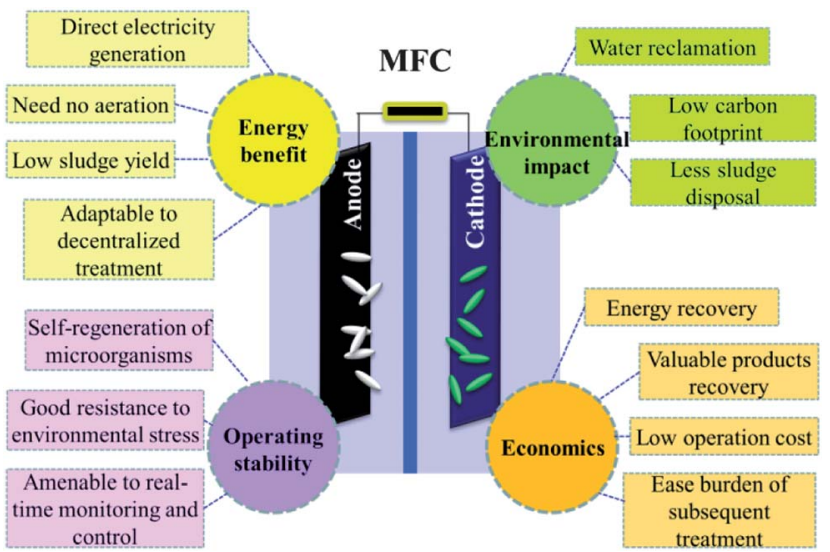

Fig. 1 Potential benefits of MFCs for energy, environmental, operational and economic sustainability.

industries. Thus, theoretically it is possible to turn wastewater treatment into a self-sufficient or even a net energy-producing process, although energy loss is unavoidable and could be considerable in a practical conversion process. The energy balance analysis of an MFC can be conducted based on its electricity generation and energy consumption.

One of the most commonly-quoted advantages of MFCs is their capability to directly extract electric energy from organic matters in wastewater. Unlike other energy products such as $\mathrm{CH}_{4}$ or $\mathrm{H}_{2}$ produced in $\mathrm{AD}$ processes, electricity is a cleaner and more widely utilizable form of energy. Moreover, MFCs can work well at ambient temperature and thus consume less energy for temperature maintenance than $\mathrm{AD}$ reactors. It has been reported that MFCs could produce normalized energy recovery (NER) of $0.026 \mathrm{~kW} \mathrm{~h} \mathrm{~m}^{-3}$ wastewater, or $0.080 \mathrm{~kW} \mathrm{~h}$ $\mathrm{kg}^{-1}$ chemical oxygen demand (COD) from municipal wastewater. ${ }^{6,7}$ MFCs are also known as an energy-saving technology resulting from reducing aeration (for air-breathing cathode MFC) and less sludge production than the conventional activated sludge processes. ${ }^{8-11}$ It is estimated that, according to the state-of-the-art practice for domestic wastewater treatment, an MFC would only consume $0.024 \mathrm{~kW}$ or $0.076 \mathrm{~kW} \mathrm{~h} \mathrm{~kg}^{-1}$-COD in average (mainly for reactor feeding and mixing), ${ }^{6}$ about one order of magnitude less than activated sludge-based aerobic processes $\left(\sim 0.3 \mathrm{~kW}\right.$ or $0.6 \mathrm{~kW} \mathrm{~h} \mathrm{~kg}{ }^{-1}$-COD).$^{12}$ Therefore, a positive energy balance in domestic wastewater treatment is theoretically achievable by MFCs alone on a liter scale (Fig. 2).

However, in a real-world application, the goal of energy neural is still far from success, especially for the MFCs at larger scales. Generally, the maximum power output in the liter-scale MFCs are in the order of several $\mathrm{W} \mathrm{m}^{-3}$ (Table 1), which is three orders of magnitude lower than the target value of $1 \mathrm{~kW} \mathrm{~m}^{-3}$ (given an organic loading rate of $10 \mathrm{~kg}^{-\mathrm{COD} \mathrm{m}}{ }^{-3}$ day $^{-1}$ ) for an energy self-sufficient implementation. ${ }^{13}$ The unfavorable solution characteristics (e.g. low conductivity and $\mathrm{pH}$ buffer capability of most wastewaters) $)^{10,14,15}$ and the complexity of wastewater composition ${ }^{16,17}$ further add up to the difficulty in power density improvement. A detailed overview of those limitations can be found elsewhere. ${ }^{10,18-21}$ 

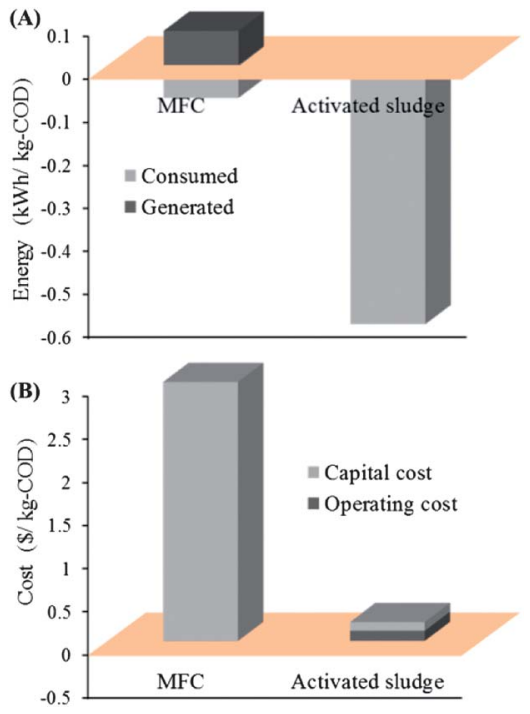

Fig. 2 (A) Energy balance; and (B) estimated costs of an MFC and an activated sludge system for municipal wastewater treatment. For the energy balance calculation, the energy generation and consumption associated with sludge treatment is not included.

Of course, there is still space for power and energy improvement. For example, considering a much higher volumetric energy content of wastewater (about $1.2 \mathrm{~kW} \mathrm{~h} \mathrm{~m}^{-3}$ for municipal wastewater assuming a COD of $300-400 \mathrm{mg} \mathrm{L}^{-1}$ and even higher for food-industry wastewater), ${ }^{5}$ further improvement in energy extraction by MFCs is possible. ${ }^{22}$ In the meantime, through optimizing reactor configuration and hydraulics or adopting a decentralized wastewater treatment mode (which can avoid energy consumption for long-distance transport of water and are highly suitable for smaller-scale facilities like $\mathrm{MFCs}^{23}$ ), the energy consumption might be further reduced.

\subsection{Environmental impacts}

Environmental sustainability of a wastewater treatment process means that the effluent quality should meet the standards of water reclamation and reuse. Meanwhile, the transfer of contamination from aqueous to atmosphere and solid phases (e.g., excess sludge) should be diminished to an environmentally acceptable level.

Although both MFCs and AD processes allow simultaneous pollutant removal and energy recovery, in most cases MFCs show a better decontamination performance, especially for removal of aqueous recalcitrant contaminants including many persistent contaminants. ${ }^{31}$ This superior performance of MFC is likely due to the co-existence of anaerobic and aerobic microenvironments, which allows many reactions that are inherently incapable by strict anaerobic or aerobic technologies. So far, the high capability of MFCs and their derived reactors (e.g., microbial electrolysis cells) has been demonstrated for efficient removal of aqueous contaminants, such as recalcitrant organics, ${ }^{32-34}$ nutrients, ${ }^{35}$ sulfur compounds, ${ }^{36,37}$ and metals, ${ }^{38,39}$ and to achieve good effluent quality (COD $\left.<20 \mathrm{mg} \mathrm{L}^{-1}\right) .{ }^{14}$ This feature is especially valuable today because the water quality standards are getting increasingly stringent while the discharge of anthropic chemicals (e.g., various dyes, cosmetics and medicines) is increasing.

MFCs may also have a low carbon footprint, arising from less fossil-related $\mathrm{CO}_{2}$ production as a result of low energy consumption as well as ability for $\mathrm{CO}_{2}$ sequestration in some reactors with a specifically designed cathode. ${ }^{\mathbf{4 0 - 4 2}}$ Additionally, the MFC process has low sludge production. Compared with the sludge yield of $0.4-0.8$ volatile suspended solids (VSS) $\mathrm{g}^{-1}$-COD in an activated sludge system, an MFC produces around 0.1 g-VSS $\mathrm{g}^{-1}$-COD. ${ }^{6}$ Thus, the secondary pollution risks and extra energy consumption associated with sludge disposal can be greatly reduced. ${ }^{43}$

Many of these environmental benefits of MFCs are yet to be experimentally demonstrated in real-world facilities. Several preliminary studies indicate that the realization of such benefits in a practical wastewater treatment process is not easy. For example, the conversion of $\mathrm{CO}_{2}$ to organic compounds such as $\mathrm{CH}_{4}$ and acetate is very slow and energy-intensive, and the autotrophic organisms that carry out those processes may not be able to compete with heterotrophic organisms in case of microbial contamination. ${ }^{\mathbf{4}}$ Moreover, many of the materials used in MFCs such as catalysts, electrodes, and separators are fossil fuel based and might have negative environmental impacts. Hence, the overall environmental impacts of MFCs for wastewater treatment need more comprehensive evaluation.

\subsection{Operating stability}

For a practical application, the treatment process should also be robust and stable without extra investment of much energy and resources for maintenance in the long-term run. In MFCs, microorganisms typically develop into a biofilm on electrodes,

Table 1 Electricity generation performance of liter-scale MFCs for wastewater treatment

\begin{tabular}{|c|c|c|c|c|c|}
\hline Wastewater & Reactor volume $(L)$ & Max. power density $\left(\mathrm{W} \mathrm{m}^{-3}\right)$ & NER (kW h kg ${ }^{-1}$-COD) & CE (\%) & Ref. \\
\hline Synthetic & 20 & 11 & - & - & 24 \\
\hline Municipal & 20 & 0.17 & 0.003 & 0.3 & 25 \\
\hline Synthetic & 7.5 & 0.39 & - & 50 & 27 \\
\hline Municipal & 4 & - & 0.08 & 10.7 & 6 \\
\hline Municipal & 2 & 0.18 & 0.04 & - & 28 \\
\hline
\end{tabular}


which confers their good resistance to toxic substances and environmental fluctuations (e.g. $\mathrm{pH}$ and temperature variations). ${ }^{16}$ One unique advantage of MFCs over other biotechnologies is its good amenability to real-time monitoring and control by means of electrochemical reactions; hence the process robustness can be further strengthened. ${ }^{45-47}$ Several MFCs with good long-term performance (with stable operation for up to two years) have been reported for treating real wastewater in both bench-scale ${ }^{33,48}$ and pilot studies. ${ }^{6,25,26}$

However, there are also a number of studies reporting deteriorated performance of MFCs during long-term operation. Especially, maintaining the predominance of electrochemically active microorganisms (EAMs) in a complex wastewater environment could be challenging. ${ }^{28,49}$ The variation of the operating environment (e.g., accumulation of protons and hydroxyl ions in different chambers $\left.{ }^{50}\right)$ and declined functions of electrode/membrane materials also affect long-term performance. Electrode deterioration frequently occurs, resulting from fouling, ${ }^{25,51,52}$ corrosion, ${ }^{53}$ clogging of electrode materials, and deactivation of catalysts. Additionally, there is always gradual fouling of the separators over time. ${ }^{54-56}$ All these factors may impair the long-term stability of MFCs for wastewater treatment. To date, some attempts have been made to address these problems, but truly effective and practical countermeasures are still lacking. ${ }^{43}$

\subsection{Economics}

Poor economic viability might be the primary barrier for advancing MFCs to a practical application (Fig. 2). The cost of MFCs mainly includes initial capital investment and operation/ maintenance expenses associated with energy, chemicals and materials consumption, while the economic revenue may come from governmental subsidizing and the fee charged from the contaminant discharge. Additional revenue can be from the recovery of energy (e.g., electricity in MFC and $\mathrm{CH}_{4} / \mathrm{H}_{2}$ in anaerobic digesters) and value-added products (e.g., fertilizer and poly-hydroxybutyrate). ${ }^{57}$

2.4.1 Operation cost. The operation of MFCs could be energy saving as compared to many other treatment technologies. $^{58-60}$ Based on the aforementioned energy balance analysis, it is estimated that an MFC can theoretically generate a net NER

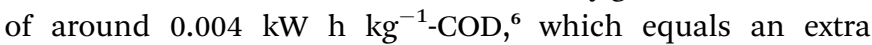
economic revenue of about $\$ 0.0005 \mathrm{~kg}^{-1}$-COD given an average electricity price of $\$ 0.12 \mathrm{~kW} \mathrm{~h}^{-1}$. ${ }^{61}$ In comparison, the state-ofthe-art treatment cost for an activated sludge-based WWTP is about $\$ 0.12 \mathrm{~kg}^{-1}$-COD, assuming an energy consumption of $0.6 \mathrm{~kW} \mathrm{~h} \mathrm{~kg}^{-1}-\mathrm{COD}^{12}$ and that $60 \%$ of the operation cost is used for energy consumption. Additionally, a possible recovery of value-added products from wastewater may further strengthen the economic justification of MFCs. ${ }^{62,63}$ However, the achievable profit of such processes remains under debate in light of the usually low product yield and the high cost for product extraction and purification.

2.4.2 Capital cost. The capital costs of MFCs are still extraordinarily high at the present stage, due to the use of expensive electrodes (including carrier material, current collector and catalyst $)^{10}$ and separator materials..$^{64}$ For example, Ultrex membranes, one of the most often-used separators in the larger-scale MFCs, cost approximately $\$ 110 \mathrm{~m}^{-2}$. It is estimated that, even with relatively cheap carbon cloth electrodes and a nonwoven fabric separator that have been demonstrated in several studies, ${ }^{59}$ the overall capital costs of an air-cathode MFC for municipal wastewater treatment would still reach $\$ 3 \mathrm{~kg}^{-1}$ COD (or approximately $\$ 1.5 \mathrm{~m}^{-3}$-municipal wastewater). This estimation is based on the state-of-the-art levels of MFC configuration and treatment capability: ${ }^{59}$ treatment capacity of $25 \mathrm{~kg}-\mathrm{COD} \mathrm{m} \mathrm{d}^{-1}$, cathode of $\$ 1500 \mathrm{~m}^{-2}$, anode of $\$ 100 \mathrm{~m}^{-2}$, separator of $\$ 1 \mathrm{~m}^{-2}$, reactor of $\$ 5000 \mathrm{~m}^{-3}$, and a lifetime of 10 years. This capital cost is 30-times higher than that of a conventional activated sludge system. ${ }^{10}$ Therefore, the capital cost of MFC technology must be substantially reduced before its commercialization.

To conclude, the energy output of MFCs is still far from meeting an energy-neutral operation at practical scales, the environmental benefit is not straightforward, the process performance tends to decline over a long-term operation, and the materials of MFCs are generally cost-prohibitive. While continuing improvement in those aspects can be expected with the ongoing research, it seems some of the challenges such as a relatively high capital cost might remain, making MFCs competitively unfavorable. To meet the sustainability criteria, more suitable strategies other than advancing MFC technology alone should be sought. In our opinion, integrating MFCs with other processes might be a more feasible avenue. Several possible approaches of the integration and the reasons are discussed below.

\section{Taking advantage of synergies between MFC and other treatment technologies}

\subsection{Integration of $\mathrm{AD}$ for pre-fermentation}

There has been growing interest in combining AD with MFCs for wastewater treatment, resulting from complementary synergy between these two processes ${ }^{65}$ In general, MFCs are more suitable for treating medium and low-strength wastewaters with a relatively simple composition, while $\mathrm{AD}$ has a clearly competitive advantage in dealing with high-strength wastewaters. Many practical wastewaters such as brewery ${ }^{66}$ and winery wastewaters, ${ }^{15}$ due to a high fraction of particulate and fermentative substrates, cannot be efficiently used by EAMs, as suggested by a recent report that MFCs cannot compete with AD when treating sludge for energy recovery ${ }^{67}$ Pre-hydrolysis and fermentation of particulates and complex substrates in $\mathrm{AD}$ could provide more better-utilizable substrates (mainly volatile fatty acids) for electricity generation in an MFC. ${ }^{68,69}$ MFCs can also degrade the remaining organics in $\mathrm{AD}$ effluent, thereby not only further recovering energy from the waste stream but also polishing the effluent quality while avoiding the energy-intensive aerobic post-treatment step. ${ }^{70,71}$ Such an AD-MFC integrated process for enhanced pollutant removal and energy recovery from various wastewaters has been demonstrated. ${ }^{72-76}$ 
Besides, several recent studies showed that bioelectrochemical systems can also be used to effectively monitor the $\mathrm{AD}$ reactor status $^{77}$ or even to improve stability and remediate AD systems that exhibited process failure. ${ }^{78}$

\subsection{Struvite precipitation for enhanced phosphate recovery}

Phosphorus removal and recovery has become a key issue for wastewater treatment because of the stricter regulations. In addition, due to the increasing gap between a dwindling reserve of phosphorus and a growing demand on its supply, ${ }^{79}$ recovery of the valuable phosphorus resources contained in wastewater is becoming attractive. One appealing approach for this is to produce struvite $\left(\mathrm{MgNH}_{4} \mathrm{PO}_{4} \cdot 6 \mathrm{H}_{2} \mathrm{O}\right)$ or other phosphate-based precipitate, which are known as an excellent slow-release fertilizer. ${ }^{80-82}$ In this process, phosphate, ammonia and magnesium are recovered simultaneously. ${ }^{83}$ This method can be used in combination with MFCs for more sufficiently exploiting the available resources and improving treatment performance. In particular, it is very suitable for the treatment of wastewater rich in nitrogen and phosphorous such as swine wastewater and urine. ${ }^{\mathbf{8 4}}$ Sufficient recovery of the nutrients through struvite precipitation can greatly increase the economic benefits of the treatment process (this would be even more significant considering the increasing scarcity and hence the high strategic value of phosphate) and alleviate possible ammonia-induced microbial suppression, thereby improving electricity generation in the subsequent MFC treatment. Meanwhile, MFCs as a post-treatment step can substantially remove the organics (which is impossible by struvite precipitation) and recover the energy in organic compounds. By adopting such an integrated process, Zang et al. successfully recovered $94.6 \%$ of phosphate and $28.6 \%$ of ammonia from urine, and achieved $64.9 \%$ COD removal and $2.6 \mathrm{~W} \mathrm{~m}^{-3}$ power output. ${ }^{85}$ Interestingly, an MFC can also be incorporated into a struvite reactor to enhance the struvite precipitation efficiency, due to a high local $\mathrm{pH}$ at the MFC cathode ${ }^{86}$ or accelerated release of phosphate from sewage sludge with high selectivity (Fig. 3). ${ }^{52,86}$ Those prior studies imply good synergy between these two technologies. Of course, the struvite precipitation performance is strongly dependent on the solution chemistry

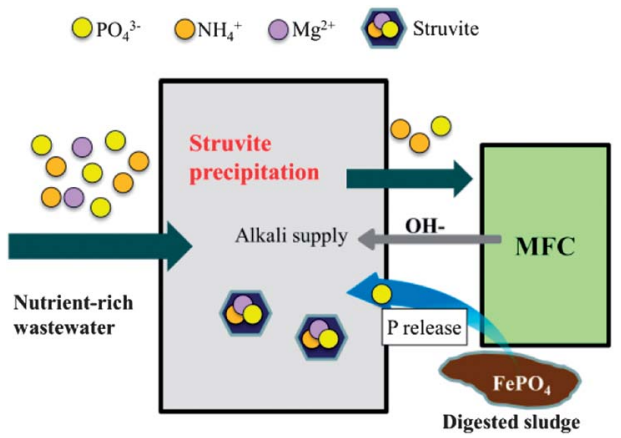

Fig. 3 Schematic diagram of integrating struvite precipitation and MFC for enhanced phosphate recovery. (mainly wastewater composition), hence the application range of such processes would be constrained.

\subsection{Algae for improved removal of nutrient and production of biomass}

For treatment of relatively low-nutrient wastewater, struvite precipitation is unsuitable while MFCs are generally inefficient for nutrient removal. Algal treatment in connection with MFCs could be highly desirable. It is well known that many photoautotrophs, such as algae and cyanobacteria, ${ }^{87}$ can efficiently absorb nutrients from water for biomass synthesis. ${ }^{88}$ Therefore, after COD removal by an MFC, algal treatment may further remove the residual nutrients and improve water quality. Besides, there are also other concomitant environmental and energy benefits, such as $\mathrm{CO}_{2}$ sequestration ${ }^{89}$ and biodiesel extraction $^{90}$ from the produced algal biomass or even using biomass for extra electricity production. ${ }^{91}$ It was reported that the removal efficiencies of total organic carbon, nitrogen and phosphorus in an MFC-algae integrated system reached up to 99.6, 87.6 and $69.8 \%$ respectively, accompanied with a stable power density of $68 \mathrm{~mW} \mathrm{~m}^{-2}$ and a microalgae biomass yield of $0.56 \mathrm{~kg} \mathrm{~m}{ }^{-3} .^{92}$ Through optimizing the reactor configuration and imposing self-buffering, ${ }^{93}$ the nutrient recovery ratio was further increased (98\% for nitrogen and $82 \%$ for phosphate) and a higher power density (up to $2.2 \mathrm{~W} \mathrm{~m}^{-3}$ ) was steadily achieved during a one-year operation. In addition to nutrient uptake, the algal treatment can also efficiently remove various heavy metals and many other contaminants in water through biosorption, ${ }^{94}$ thus further purifying the MFC effluent.

\subsection{Membrane separation for water reclamation}

To ensure good effluent water quality, a deep treatment for sufficiently removing the suspended solids (including planktons) and some residual recalcitrant substances would be necessary. For this purpose, membrane technology would be an attractive option, and has been widely adopted to efficiently separate pollutants or recycle valuable chemical products ${ }^{95}$ and meanwhile to produce high-quality water. ${ }^{23}$ There have been several successful attempts to integrate the membrane separation process with MFCs, either through sequential linking or through direct coupling, of both. ${ }^{\mathbf{9 6}, 97}$ For instance, the integration of hollow-fiber ultrafiltration membranes into a tubular MFC for municipal wastewater treatment was found to substantially improve the effluent quality, with effluent turbidity $<1$ NTU and COD removal $>90 \% .{ }^{98}$ Wang et al. reported a low-cost electrochemical membrane bioreactor (EMBR) with good effluent quality and theoretically net energy production. ${ }^{99}$ In their system, the treated wastewater from the anodic chamber directly flew through a layer of non-woven cloth and a graphite felt, the latter serving as both a filter and the cathode. Meanwhile, air was continuously diffused from the atmosphere into the microbial-colonized graphite felt cathode, where simultaneous ORR, nitrification and denitrification reactions occurred at high efficiency (Fig. 4). Furthermore, no excess sludge was discharged over a two-month operation. 
The above suggests that more benefits can be achieved and many of the limitations of MFCs can be eased up by combining it with other treatment technologies. However, such integrations may also bring in some new challenges as detailed below. To maximize the synergies and reduce possible negative impacts, it is important that different technologies can be integrated appropriately according to the actual wastewater properties and environmental conditions. Hence, the process design is critical. In the following, we propose an exemplary and hypothetical scenario where several bioenergy/chemical recovering and enhanced treatment steps are optionally integrated by taking into account the sustainability criteria.

\section{MFC-centered hybrid process-a future paradigm for improving treatment sustainability}

\subsection{Hypothetical process for wastewater refinery}

Similar to oil refinery, in a wastewater refinery concept the value of each product stream should be maximized, while the output of waste streams should be minimized. In addition, the investment of energy or resources into this process should also be controlled at a reasonable level. Based on these principles, we hypothesize that the above discussed technologies, including $\mathrm{AD}$, struvite precipitation, algae treatment and membrane filtration, can be partially or all incorporated into a MFC-centred treatment chain for maximizing the treatment sustainability. The schematic process flow is shown in Fig. 5.

As the first step, a settling tank and other primary treatment facilities (e.g., bar screens and debris basin as in most of the existing wastewater treatment plants-WWTPs) can be adopted to remove the majority of the non-utilizable fractions and meanwhile reduce the risk of the reactor clogging in the subsequent treatment steps. Then, depending on the wastewater properties, the wastewater can be treated via three different paths: (1) wastewater with a low organic loading can be directly fed into an MFC system; (2) high-strength wastewater might need to be treated firstly in an anaerobic reactor for prefermentation before entering into the MFC system, for biogas production and for generating a favourable wastewater

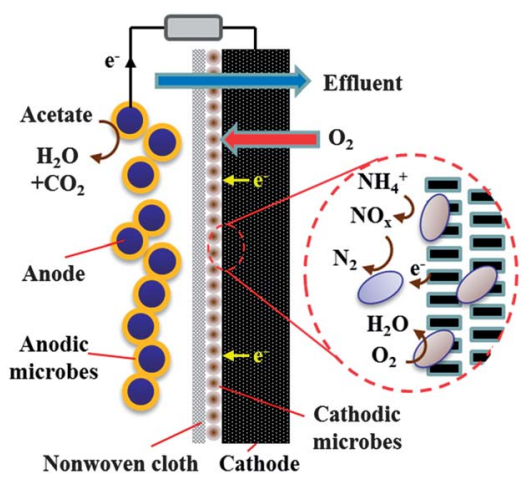

Fig. 4 Schematic diagram of an air-breathing cathode EMBR for wastewater treatment. ${ }^{99}$

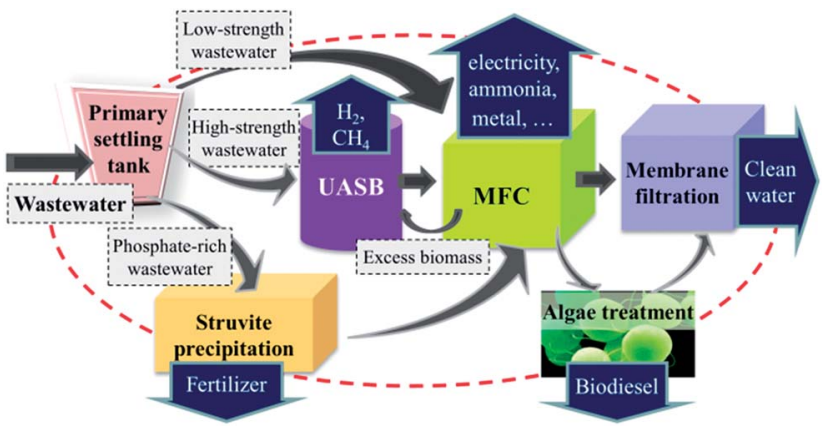

Fig. 5 Process flow of a hypothetical MFC-centered hybrid process for wastewater refinery. The arrows represent the water/sludge flow direction.

composition for the subsequent MFC treatment; to support the energy self-sustained operation of a WWTP, the produced biogas can be converted into electricity via combined heat and power systems, and it is estimated that in this way up to $28 \%$ of the energy potential in wastewater can be recovered as electricity by using an upflow anaerobic sludge blanket (UASB) reactor, ${ }^{\mathbf{1 0 0}}$ and the produced heat can in turn be used to maintain the reactor temperature; and (3) phosphate-rich wastewater can undergo a struvite precipitation step for nutrient recovery prior to MFC treatment (depending on the COD loading, an AD pre-fermentation step can also be optionally inserted).

Subsequently, in MFCs the remaining organics are further exploited for energy production and possible recovery of a wide range of valuable products. Nevertheless, the MFC treatment may be insufficient for lowering the aqueous nutrients to an acceptable level yet, especially for nutrient-rich wastewaters like urine or swine wastewater. ${ }^{\mathbf{1 0 1}}$ Therefore, the MFC effluent can be subjected to algal treatment for further improving the effluent quality and lifting the energy output, as well as environmental benefits from wastewater. ${ }^{88}$

And last, to yield high-quality water that meets the reclamation standard, membrane filtration processes such as ultrafiltration, nanofiltration or reverse osmosis can be incorporated as a deep-treatment step to further polish the water or even to further extract useful products from the effluent stream.

Notably, as an important part of the wastewater treatment, the produced excess sludge from the treatment processes (e.g., primary treatment and bioreactors) could also be utilized as a source of energy and resources. Thus, it is appropriate and necessary to also incorporate sludge treatment into the wastewater refinery process. In light of the complexity and biocalcitrancy of sludge as a feedstock for MFCs (proteins and carbohydrates are enveloped in the microbial matrix of the cells and EPS), ${ }^{102}$ an AD pretreatment of sludge could be helpful. ${ }^{103}$ One possible strategy would be to recirculate the excess sludge from an MFC to a UASB for digestion, and then the digested sludge can be further degraded in MFCs, thereby producing extra energy and minimizing the sludge discharge. The synergetic effects between AD and MFCs can be further maximized if MFCs can be designed in some way to simultaneously remove the inhibitive substances produced in sludge fermentation. ${ }^{\mathbf{3 4 , 1 0 4}}$ 
As thus, with a rational integration of multiple technologies (many of which can be optionally selected and flexibly deployed in the overall process), a maximized recovery of energy, clean water and other resources from wastewater can be achieved. Taking the energy production as an example, assuming that the ratio of energy recovery (relative to the energy content of wastewater given a COD concentration of $500 \mathrm{mg} \mathrm{L}^{-1}$ ) from the $\mathrm{AD}, \mathrm{MFC}$ and algae treatment steps are $28 \%,{ }^{100} 10 \%,{ }^{6}$ and $3 \%$ (ref. 93) respectively, in total $41 \%$ of the chemical energy would be recovered, which theoretically would turn the treatment process into a net energy producer considering that the energy consumption of wastewater treatment would account for no more than $10 \%$ of the energy content. An additional advantage of such an MFC-centered treatment process over conventional systems is that a decentralized treatment concept can be greatly favored due to less restriction on running the site and origin of energy source. For example, the treatment facilities can be deployed at some off-grid places such as farming fields (important non-point agricultural pollution source) and eutrophic lakes for self-sustained treatment (solar energy can be well utilized as an extra energy source by specifically designed MFC configurations). Of course, energy loss could be exaggerated in a scaled system, and the actual energy performance is still to be experimentally demonstrated.

It is worth noting that here we only give an exemplary process as to how several wastewater treatment technologies could be integrated to achieve sustainable treatment. The actual design would be case-specific and depend heavily on the wastewater properties, operating conditions and other related criteria.

\subsection{Challenges of the hybrid processes}

There will be great challenges to achieve these envisioned advantages of the hybrid processes and to realize their practical implementation.

First of all, the high cost, low power density of MFCs and difficulty for reactor scaling-up have been and will continue to be primary barriers for practical implementation of both MFCs and such a hybrid process. ${ }^{19}$ Although better overall performances in economics and energy production can be expected in a MFC-centered hybrid system, the ultimate success of this system would still heavily rely on further breakthroughs of MFC technology. Because of the offsetting effects of other treatment steps, the improvement in power density and economics of MFCs to achieve self-balanced treatment could be less as compared to that of advancing MFC technology alone, thereby making such hybrid systems more feasible to be realized. An important task will be acknowledging to what extent MFCs need to be improved to enable a sustainable operation of such a hybrid process.

Secondly, the combination might add up to the complexity of the treatment process, hence creating more challenges for process optimization and maintenance. The different treatment steps vary considerably in their functions (i.e., contributing differently to various aspects of the sustainability criteria), and their performances are interrelated. For example, when treating high-strength organic wastewater, poor AD performance might lead to decreased electricity generation in MFCs and increase fouling of the subsequent membrane separation step. Furthermore, while energy can be derived from all the steps of AD, MFC and algal treatment, they may require different economic or environmental expenses to achieve comparable energy recovery. For hybrid processes there is inevitably a counterbalance between the multiple sustainability criteria. For instance, some enhanced purification technologies, such as membrane filtration for deep treatment, electrodialysis for improved phosphate recovery, ${ }^{105}$ and advanced oxidation for promoted recalcitrant degradation, ${ }^{106}$ can bring better effluent quality but usually at the cost of higher energy consumption. Hence, difficulty would arise in balancing the energy/resource gains, environmental impacts, process stability and the economics in MFCs and between different treatment units. Although the current economic values of products such as struvite, clean water, methane, biodiesel are relatively low, the added complexity in a hybrid system will be paid off with increasing the demand on sustainability and elevated product values due to the depleting resources.

Lastly, we should be aware that, along with many envisioned positive synergies, the introduction of other processes may also bring new problems. For example, the use of membrane separation as a polishing step would give rise to membrane fouling problems; algae in photosynthesis processes can suffer from self-shading; during struvite precipitation some hazardous metals may be co-deposited, and the alkaline effluent may impair the microbial activity in the subsequent treatment steps. Therefore, a balanced evaluation of all favorable and unfavorable factors should be conducted to guide the process design and operation.

\section{The way forward}

\subsection{Scaling up MFCs to a practical level}

To make MFCs suitable for real-world applications, system scaling up would be inevitable. This requires not only increasing the reactor size and treatment capacity to a practical level, but also achieving levels of useful energy. ${ }^{19}$ Although a neutral or positive energy balance has been theoretically demonstrated, there has not been an actual operation of energetically self-sustained MFCs for wastewater treatment. ${ }^{6}$ Therefore, the biggest challenge of MFCs designed for wastewater treatment application is how to simultaneously scale up the reactor size and energy output. The specific limitations associated with system scaling up include: high internal resistance, $\mathrm{pH}$ buffering, high material cost, and low efficiency of mixed culture biofilm on an electrode. ${ }^{19,58}$ Overcoming these limitations calls for further joint efforts in reactor engineering, material development and biological manipulation.

5.1.1 Engineering MFC reactors. (1) Enlarging the reactor size. Several lessons are learned from the previous scaling up efforts, and should be considered in the future reactor design. Firstly, a close distance between the anode and the cathode electrodes, and an efficient transfer of ions should be ensured to decrease internal resistance, regardless of an increased overall reactor size. This is important because a large electrode 
distance and a $\mathrm{pH}$ gradient are usually the main reasons for the high internal resistance in the large-scale systems. ${ }^{58}$ However, shortening the electrode spacing would also increase the possibility of oxygen intrusion into the anode and substrate crossover to the cathode, especially in the membrane-less MFCs. An appropriate separator will be necessary between two closely deployed electrodes, thus making it a sandwich-structured separator electrode assembly, which can be realized in either tubular or plate MFCs. Secondly, a high electrodepacking density would benefit the system performance. Increasing the electrode surface area would increase the amount of active biomass in an MFC, thereby favoring efficient wastewater treatment and energy generation. ${ }^{107}$ As a result, the volume of the reactor for pollutant removal can be reduced and the volumetric power density can be increased. A high electrode-packing density would also reduce the pressure of the footprint demand, thus eliminating the possible location limitation for MFC application. However, highly packed biofilmelectrodes may also limit mass diffusion and electron transport, and are prone to electrode clogging.

(2) MFC stacks. Because of significant challenges in reactor scaling up, MFCs may not be scaled up to a very large scale like the one of the existing treatment systems. Thus, a more feasible and perhaps unavoidable way for MFC scaling up will be to employ multiple moderately-scaled MFC units as a stack. ${ }^{58}$ It has been proven that a serial connection of multiple MFCs can substantially boost the overall output voltage, and offer high flexibility for MFC installation and modularized operation. ${ }^{\mathbf{2 9 , 1 0 8}}$ The success of such cascade-stacking systems has long been achieved for chemical fuel cells. ${ }^{109}$ However, for MFCs with biocatalyzed electrode reactions, issues such as cell voltage reversal and ionic short circuit may arise. Voltage reversal occurs as a result of unequal electrode potentials between the unit cells, likely due to unbalanced substrate distribution, ${ }^{\mathbf{1 1 0 , 1 1 1}}$ and leads to a low power output or even a failure of the whole system. ${ }^{112}$ Ionic short circuit is encountered for serial-connected MFCs that share the same anolyte or catholyte, ${ }^{\mathbf{1 1 3 , 1 1 4}}$ and may be avoided by separating the anolyte of the unit cells, but this would increase the cost for reactor construction and maintenance (e.g., extra pumps might be used to distribute the influent wastewater). It seems that a possible approach of stacking MFCs would be to create an electrical array of multiple MFC stacks by appropriately connecting the MFC cells both in series and in parallel. In this way, the unit cells from different reactor modules are connected in series to increase voltage without causing ionic short circuit; ${ }^{\mathbf{1 1 1}}$ meanwhile the MFC stacks are connected in parallel to increase the total current output. Furthermore, the multiple unit cells in each reactor module are hydraulically connected, thus ensuring sufficient substrate degradation and good treatment performance. ${ }^{\mathbf{1 1 3}}$ For example, tubular MFCs of separator-electrode assembly (SEA) configuration with an appropriate reactor length and passive air-cathodes can be adopted as the unit cells as demonstrated in Fig. 6 .

(3) Reducing capital investment. Another important challenge pertaining to MFC scaling up is the high capital cost, mainly resulted from expensive materials (e.g., electrodes and membrane/separators). Clearly, more efficient, robust, scalable

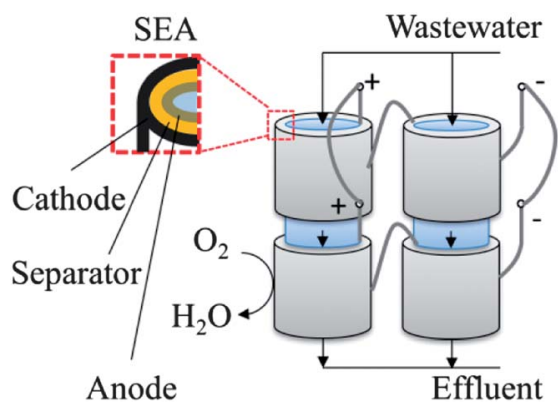

Fig. 6 Conceptual MFC stacking system (only four unit cells are depicted for simplification). The gray lines refer to electric connection. Straight arrows stand for water flow direction.

and economically affordable materials will be needed. Generally, carbon-based materials, because of a large surface area, good stability, and low cost, could be a desirable choice in this respect. ${ }^{115}$ However, their relatively low electrical conductivity is a limitation. ${ }^{19}$ The use of metal materials as current collectors may increase conductivity, but this would incur extra cost. ${ }^{116,117}$ When oxygen acts as an electron acceptor, its diffusion to the cathode electrode could affect the MFC performance. Thus, the requirement of efficient three-phase (air, water, and electrode) interface makes the selection of cathode materials even more challenging. Another high-cost component in an MFC is the separator, for which an ion exchange membrane is commonly adopted. ${ }^{55,64}$ In the quest for low-cost and fouling-resistant alternatives, many filtration materials such as non-woven cloth, ${ }^{59,99}$ ultrafiltration membranes, ${ }^{\mathbf{1 1 8}}$ and forward osmosis membrane, ${ }^{119}$ have been tested so far, but none of them seem to perfectly meet all the criteria of low cost, good mechanical strength, efficient proton transfer, and long-term stability for large-scale systems. ${ }^{\mathbf{1 2 0}}$ Future development in nanotechnology and bionics may introduce new materials with fine-tuned properties and acceptable cost. $^{\mathbf{1 2 1 - 1 2 3}}$ For example, it was reported that Geobacter sulferreducens could synthesize nanowires with metallic-like conductivity to facilitate electron transfer (ET) at the microbe-electrode interface. ${ }^{\mathbf{1 2 4 - 1 2 6}}$ Hence, such bioderived nanowires may be used to construct conductive materials, ${ }^{127}$ but their feasibility is yet to be further validated. Moreover, the possible impacts of environmental variations (e.g., wastewater composition and temperature changes) and maintenance activities (e.g., cleaning of fouled electrode) on these materials will need validation in practical systems.

(4) Power management systems. In an MFC stack consisting of multiple MFCs, how to efficiently harvest energy will become a challenge. Power management systems (PMS) have been studied to extract energy from MFCs, and they may include charge pump, DC-DC voltage boost converter, and various electric-storage capacitors. It has been demonstrated that the use of PMS with appropriate on/off switches substantially increased the output voltage of an MFC to $3.3 \mathrm{~V} \cdot{ }^{128}$ However, such devices also add up to the electric circuit complexity and increase the energy losses and cost. ${ }^{129}$ These drawbacks may be eased to a certain extent by using more efficient materials, applying accurate control, ${ }^{\mathbf{1 3 0}}$ or optimizing the design and 
operation of capacitor. ${ }^{\mathbf{1 1 2 , 1 3 1 , 1 3 2}}$ For instance, the extracellular ctype cytochromes of $G$. sulferreducens were found to function as both shuttles for electron transfer and capacitors for electron storage, ${ }^{\mathbf{1 3 3 , 1 3 4}}$ and such a property might be utilized for fabricating low-cost and environmentally-sustainable electron storage devices. ${ }^{135}$ Enhancing power control could be another useful way to aid the MFC scaling-up endeavor; to achieve this, more efficient and cost-effective PMS will be needed to continuously harvest energy from MFC operation.

5.1.2 Taking control over microbiology. The core of an MFC process mainly lies in the electrode-colonized microorganisms that simultaneously metabolize substrates and exchange electrons with an electrode. ${ }^{2,136}$ While a bioanode is an essential part of an MFC, the use of microbial catalyst also in the cathode is interesting and will undoubtedly further add to the importance of microbiology control in such a system..$^{137}$ However, the potential of such EAMs have not been fully exploited yet. Especially, the conflict between increasing biomass density and decreasing resistance of mass and electrons transport presents a big challenge. Indeed, poor biofilm conductivity usually contributes to a major fraction of the internal resistance. ${ }^{16}$ Thus, one important future task of electrode microbiology manipulation will be to create an active, conductive, and permeable biofilm. This calls for a comprehensive understanding of electrode microorganisms and their extracellular electron transfer behavior at both molecular level and microbial community and biofilm levels (Fig. 7).

An improved understanding of the molecule-level mechanisms of the microbe-electrode interactions in MFCs is yet to be achieved. To date, even the most-extensively studied EAMs, Geobacter and Shewanella, have not been fully recognized yet in their EET mechanisms. ${ }^{2}$ It is believed that EAMs can donate electrons to and/or accept electrons from a solid electrode via four possible routes: (a) periplasmic and membrane-bound cytochromes; (b) conductive nanowire; (c) redox mediators; or (d) metabolic intermediates. Recently, it was also revealed that a network of nanowire, cytochromes, and/or some conductive proteins in the extracellular polymeric matrix might be involved in long-range ET through cell-to-cell and cell-to-electrode

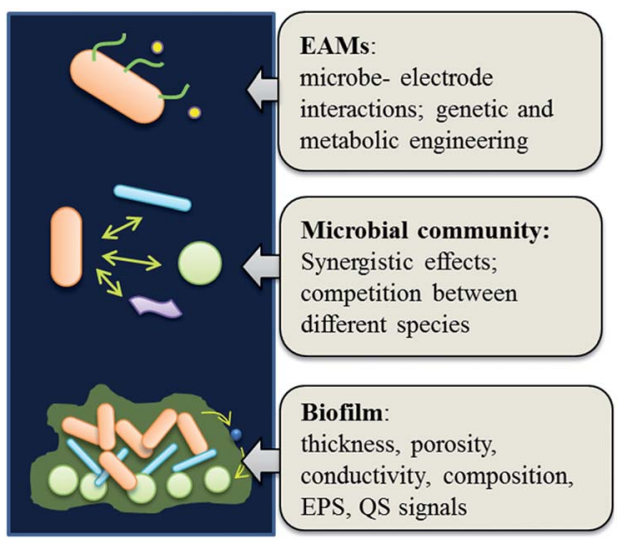

Fig. 7 Critical microbial aspects of MFCs to be better understood and manipulated. communication. ${ }^{\mathbf{1 3 8 , 1 3 9}}$ This feature is of particular significance for constructing a conductive thick biofilm. However, the specific molecular mechanisms of such long-range ET are unclear. Especially, intensive debates recently arise regarding the mechanisms of long-range ET across a G. sulferreducens biofilm. ${ }^{138,140,141}$ The c-type cytochromes, which are widely distributed in both extracellular polymeric substances and along the nanowires of this strain, were regarded as a predominant contributor to its long-range ET via electron hopping or tunneling. ${ }^{\mathbf{1 3 4 , 1 4 2}}$ However, the new finding of a network of nanowires with metallic-like conductivity suggested that metallic transfer instead of a cytochromes-based superexchange ET should be critically responsible for such biofilm conductivity. ${ }^{\mathbf{1 2 4 , 1 2 5 , 1 4 3}}$ Both theories of mechanisms will require more convincing evidence for validation, either based on direct observation of intact, actively respiring biofilm, or on direct probing into the molecule-level structure.

A similar situation was encountered with Shewanella spp. ${ }^{\mathbf{1 4 4 , 1 4 5}}$ S. oneidensis MR-1 is also known to possess filamentous nanowires, with closely arranged redox molecules along the nanowire length, and is capable of long-range ET. ${ }^{\mathbf{1 4 6}}$ However, it is unclear as to how such nanowires, and quite possibly also the membranebound c-type cytochromes, are involved in the long-range ET. ${ }^{\mathbf{1 4 7 , 1 4 8}}$ Moreover, suppression of polysaccharides synthesis in $S$. oneidensis MR-1 was found to improve ET across the biofilm, which is in contrast with in G. sulferreducens biofilms. ${ }^{149,150}$ These results hence reveal a great diversity in the mechanisms of EET among different microbial species. In light of the great diversity of EAMs in natural environment, and also the possibility of interspecies ET, ${ }^{\mathbf{1 5 1}}$ thus, an in-depth investigation into the EET mechanisms of other EAM species in addition to Geobacter and Shewanella would also be necessary. ${ }^{152,153}$

Notably, compared with the anode biofilm, the EET mechanisms of microbial cathode are even less known. Although many of the EET routes identified in the cathode so far are similar to those at the anode, the microorganisms involved and their functions seem to be different. ${ }^{154}$ Furthermore, it is unknown how the cathode-respiration microorganisms gain energy from the electron uptake process. ${ }^{155}$ Obtaining such knowledge will require substantial development in detection techniques for more efficient, accurate and even in situ analysis into the complex microbe-electrode interactions. ${ }^{\text {153,156-158 }}$ Meanwhile, gene engineering approaches ${ }^{\mathbf{1 5 9 , 1 6 0}}$ and molecular dynamic simulation techniques ${ }^{\mathbf{1 6 1 , 1 6 2}}$ may also aid in revealing the EET pathways at a molecular level.

To support an efficient and robust biofilm electrode for practical wastewater treatment, it is also essential to maintain a well-balanced microbial community consisting of EAMs and their various syntrophic partners as well as competitors. ${ }^{\mathbf{1 6 3 - 1 6 5}}$ Some efforts have been initiated to gain a better characterization and engineering of microbes, such as optimization of operating conditions (e.g., $\mathrm{pH}$, temperature, solution properties), ${ }^{166}$ creation of an artificial biofilm, ${ }^{167,168}$ selective enrichment of microorganisms via electrode surface modification, ${ }^{\mathbf{1 6 9}}$ or using quorum sensing (QS) signal for microbial community regulation, ${ }^{\mathbf{1 7 0 , 1 7 1}}$ but more research works are still to be conducted in practical situations for validation and improved 
control. The properties of biofilm, such as thickness, porosity, conductivity, composition and extracellular polymer substances (EPS) content, which significantly affect mass diffusion and electron transfer, ${ }^{172}$ are also critical for the microbiology control and warrant future investigations. ${ }^{\mathbf{1 2 5 , 1 7 3}}$

\subsection{Better coordinating the synergies among individual technologies}

In addition to improving individual technologies, especially MFCs, rational coordination between the individual units is also critical for the success of such MFC-centered hybrid processes. This requires a delicate optimization in both the system design and process operation, for which mathematical modelling and advanced process monitoring/control may be used.

5.2.1 Mathematical modeling. A better understanding and optimization of such complex hybrid processes may be facilitated by use of mathematical models. ${ }^{131,132}$ Specifically, two directions could be pursued: first, more detailed MFC models should be established by taking into account multiple biochemical, hydrodynamic, and electrochemical parameters; and second, global models that describe the overall MFCcentered processes and reflect the multiple sustainability criteria are needed. These might be accomplished by incorporating bioelectrochemical processes of MFCs into the existing activated sludge model and $\mathrm{AD}$ model for a uniform process simulation, and by performing multiple-factor analysis based on a life-cycle assessment (LCA) of the hybrid process. LCA analysis should proceed with caution, since there has been no successful demonstration of MFC system at a reasonable scale yet that can provide sufficient information for such analysis.

5.2.2 Process monitoring and control. To enable a robust and stable treatment process, online monitoring and real-time process control must be afforded. MFCs are inherently amendable to a real-time monitoring and control, because the electrochemical parameters such as electric current and electrode potential can function as useful indicators of the system status and treatment levels ${ }^{45-47,174}$ and offer effective means for process control. ${ }^{175,176}$ This is a relatively untapped but highly promising area for advancing MFC applications. To this end, an in-depth and comprehensive understanding of the complex relationships among engineering, microbiology and electrochemistry in MFCs should be acquired, and more monitoring/control factors (including not only electrochemical parameters but also conventional biological indexes, water quality parameters and various mass transfer processes) should be considered. A detailed list of these various factors is given in Fig. 8. Considering that MFC itself can only provide an electric signal, more complementary detection techniques would also be required for monitoring many other parameters. In this regard some attempts have already been initiated. For example, a non-destructive confocal Raman microscopy method was recently reported to in situ determine the spatial redox electrochemistry of MFC biofilms; ${ }^{\mathbf{1 5 7}}$ A nuclear magnetic resonance micro-imaging system was used to successfully measure the spatially and temporally resolved effective diffusion coefficients in electrode biofilms. ${ }^{177}$ Such

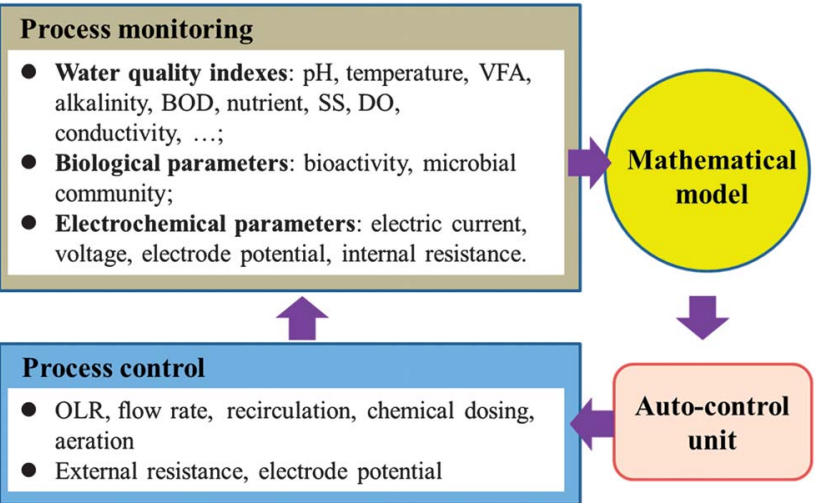

Fig. 8 Flow chart of an online monitoring and control system for MFCs.

direct monitoring of the biofilm evolution and mass transfer process would offer more straightforward and less-interfered information about the system status.

Apart from MFCs, the monitoring and control of other treatment steps should also be strengthened. Dong et al. ${ }^{178}$ reported an efficient online $\mathrm{AD}$ reactor monitoring and alert system based on the use of low-cost online detection devices and a stability index for reactor diagnosis, which could offer real-time information about the reactor status, but more rich diagnosis database and a feedback control system are yet to be developed. In other relevant fields, the advanced online sensing systems for in situ monitoring of algae, microcystin ${ }^{\mathbf{1 7 9}}$ various trace organic pollutants, ${ }^{180}$ etc. in aqueous solution may also be used in an MFC-centered hybrid system to improve the process robustness and stability.

\section{Conclusions}

In this perspective, we propose the concept of an MFC-centered hybrid process as an example to promote the practical application of MFCs and improve the sustainability of wastewater treatment process. Both the opportunities and the limitations of MFC technology to meet the multiple criteria of sustainability are analyzed. A possible paradigm of an MFC-centered hybrid system for wastewater refinery by appropriately integrating MFC with several other treatment technologies, including AD, struvite precipitation, algae treatment and membrane filtration, are presented. The challenges and future directions for scaling up MFCs to a practical level as well as for advancing the application of such hybrid processes are discussed. In light of the limited available data about practical application of MFCs and many uncertainties in future technological and economic development, this paper only presents an initial attempt to explore the possibility for applying MFCs as a sustainable technology for wastewater treatment and to guide its future development. A quantitative evaluation of the sustainability of MFCs and its hybrid processes will rely on the establishment of more statistical data, and its practical application feasibility will be subjected to field demonstration. 


\section{Acknowledgements}

The authors wish to thank the Natural Science Foundation of China (51008290 and 51278479), the Program for Changjiang Scholars and Innovative Research Team in University, China, and the NSF I-Corp program (Award \#1216511) for partial support of this study.

\section{References}

1 K. Rabaey, L. Angenent, U. Schroder and J. Keller, Bioelectrochemical systems: from extracellular electron transfer to biotechnological application, IWA Publishing, London, 2010.

2 B. E. Logan, Nat. Rev. Microbiol., 2009, 7, 375-381.

3 H. E. Muga and J. R. Mihelcic, J. Environ. Manage., 2008, 88, 437-447.

4 A. D. Levine and T. Asano, Environ. Sci. Technol., 2004, 38, 201A-208A.

5 E. S. Heidrich, T. P. Curtis and J. Dolfing, Environ. Sci. Technol., 2011, 45, 827-832.

6 F. Zhang, Z. Ge, J. Grimaud, J. Hurst and Z. He, Environ. Sci. Technol., 2013, 47, 4941-4948.

7 Z. Ge, J. Li, L. Xiao, Y. Tong and Z. He, Environmental Science \& Technology Letters, 2013, DOI: 10.1021/ez4000324.

8 Z. He, Environ. Sci. Technol., 2012, 47, 332-333.

9 S. T. Oh, J. R. Kim, G. C. Premier, T. H. Lee, C. Kim and W. T. Sloan, Biotechnol. Adv., 2010, 28, 871-881.

10 R. A. Rozendal, H. V. M. Hamelers, K. Rabaey, J. Keller and C. J. N. Buisman, Trends Biotechnol., 2008, 26, 450-459.

11 T. P. Curtis, in Environ. Microbiol., John Wiley \& Sons, Inc., 2010, pp. 301-318.

12 P. L. McCarty, J. Bae and J. Kim, Environ. Sci. Technol., 2011, 45, 7100-7106.

13 K. Rabaey and W. Verstraete, Trends Biotechnol., 2005, 23, 291-298.

14 J. Yu, J. Seon, Y. Park, S. Cho and T. Lee, Bioresour. Technol., 2012, 117, 172-179.

15 R. D. Cusick, P. D. Kiely and B. E. Logan, Int. J. Hydrogen Energy, 2010, 35, 8855-8861.

16 A. P. Borole, G. Reguera, B. Ringeisen, Z. W. Wang, Y. J. Feng and B. H. Kim, Energy Environ. Sci., 2011, 4, 4813-4834.

17 T. H. J. A. Sleutels, L. Darus, H. V. M. Hamelers and C. J. N. Buisman, Bioresour. Technol., 2011, 102, 1117211176.

18 T. H. Pham, P. Aelterman and W. Verstraete, Trends Biotechnol., 2009, 27, 168-178.

19 B. E. Logan, Appl. Microbiol. Biotechnol., 2010, 85, 16651671.

20 F. Harnisch and U. Schröder, Chem. Soc. Rev., 2010, 39, 4433-4448.

21 B. E. Logan, B. Hamelers, R. A. Rozendal, U. Schrorder, J. Keller, S. Freguia, P. Aelterman, W. Verstraete and K. Rabaey, Environ. Sci. Technol., 2006, 40, 5181-5192.

22 O. Lefebvre, A. Uzabiaga, I. Chang, B. H. Kim and H. Ng, Appl. Microbiol. Biotechnol., 2011, 89, 259-270.
23 M. A. Shannon, P. W. Bohn, M. Elimelech, J. G. Georgiadis, B. J. Marinas and A. M. Mayes, Nature, 2008, 452, 301-310.

24 A. Dekker, A. T. Heijne, M. Saakes, H. V. M. Hamelers and C. J. N. Buisman, Environ. Sci. Technol., 2009, 43, 90389042.

25 D. Jiang, M. Curtis, E. Troop, K. Scheible, J. McGrath, B. Hu, S. Suib, D. Raymond and B. Li, Int. J. Hydrogen Energy, 2011, 36, 876-884.

26 L. Zhuang, Y. Yuan, Y. Wang and S. Zhou, Bioresour. Technol., 2012, 123, 406-412.

27 P. Clauwaert, S. Mulenga, P. Aelterman and W. Verstraete, Appl. Microbiol. Biotechnol., 2009, 83, 241-247.

28 F. Zhang, Z. Ge, J. Grimaud, J. Hurst and Z. He, Bioresour. Technol., 2013, 136, 316-321.

29 S. Cheng and B. E. Logan, Bioresour. Technol., 2011, 102, 4468-4473.

30 Z. Li, L. Yao, L. Kong and H. Liu, Bioresour. Technol., 2008, 99, 1650-1655.

31 L. Huang, S. Cheng and G. Chen, J. Chem. Technol. Biotechnol., 2010, 86, 481-491.

32 S. Kalathil, J. Lee and M. H. Cho, New Biotechnol., 2011, 29, 32-37.

33 F. Aulenta, L. Tocca, R. Verdini, P. Reale and M. Majone, Environ. Sci. Technol., 2011, 45, 8444-8451.

34 A. P. Borole, C. Y. Hamilton and D. J. Schell, Environ. Sci. Technol., 2012, 47, 642-648.

35 B. Min, J. Kim, S. Oh, J. M. Regan and B. E. Logan, Water Res., 2005, 39, 4961-4968.

36 K. Rabaey, K. Van de Sompel, L. Maignien, N. Boon, P. Aelterman, P. Clauwaert, L. De Schamphelaire, H. T. Pham, J. Vermeulen, M. Verhaege, P. Lens and W. Verstraete, Environ. Sci. Technol., 2006, 40, 52185224.

37 F. Zhao, N. Rahunen, J. R. Varcoe, A. Chandra, C. AvignoneRossa, A. E. Thumser and R. C. T. Slade, Environ. Sci. Technol., 2008, 42, 4971-4976.

38 Z. Li, X. Zhang and L. Lei, Process Biochem., 2008, 43, 13521358.

39 B. Zhang, H. Zhao, C. Shi, S. Zhou and J. Ni, J. Chem. Technol. Biotechnol., 2009, 84, 1780-1786.

40 K. P. Nevin, T. L. Woodard, A. E. Franks, Z. M. Summers and D. R. Lovley, Ambio, 2010, 1, e00103-00110.

41 M. Villano, G. Monaco, F. Aulenta and M. Majone, J. Power Sources, 2011, 196, 9467-9472.

42 M. Villano, F. Aulenta, C. Ciucci, T. Ferri, A. Giuliano and M. Majone, Bioresour. Technol., 2010, 101, 3085-3090.

43 J. M. Foley, R. A. Rozendal, C. K. Hertle, P. A. Lant and K. Rabaey, Environ. Sci. Technol., 2010, 44, 3629-3637.

44 F. Aulenta, A. Canosa, P. Reale, S. Rossetti, S. Panero and M. Majone, Biotechnol. Bioeng., 2009, 103, 85-91.

45 J. M. Tront, J. D. Fortner, M. Plötze, J. B. Hughes and A. M. Puzrin, Biosens. Bioelectron., 2008, 24, 586-590.

46 L. Peixoto, B. Min, G. Martins, A. G. Brito, P. Kroff, P. Parpot, I. Angelidaki and R. Nogueira, Bioelectrochemistry, 2011, 81, 99-103.

47 Z. Liu, J. Liu, S. Zhang, X. H. Xing and Z. Su, Bioresour. Technol., 2011, 102, 10221-10229. 
48 X. Li, N. Zhu, Y. Wang, P. Li, P. Wu and J. Wu, Bioresour. Technol., 2013, 128, 454-460.

49 Y. Zhang and I. Angelidaki, Water Res., 2012, 46, 2727-2736. 50 Y. H. Jia, H. T. Tran, D. H. Kim, S. J. Oh, D. H. Park, R. H. Zhang and D. H. Ahn, Bioprocess Biosyst. Eng., 2008, 31, 315-321.

51 S. T. Lohner, D. Becker, K. M. Mangold and A. Tiehm, Environ. Sci. Technol., 2011, 45, 6491-6497.

52 F. Fischer, C. Bastian, M. Happe, E. Mabillard and N. Schmidt, Bioresour. Technol., 2011, 102, 5824-5830.

53 S. J. You, J. Y. Wang, N. Q. Ren, X. H. Wang and J. N. Zhang, ChemSusChem, 2010, 3, 334-338.

54 Z. Liu, J. Liu, S. Zhang and Z. Su, Biotechnol. Lett., 2008, 30, 1017-1023.

55 M. J. Choi, K. J. Chae, F. F. Ajayi, K. Y. Kim, H. W. Yu, C. W. Kim and I. S. Kim, Bioresour. Technol., 2011, 102, 298-303.

56 J. Xu, G. P. Sheng, H. W. Luo, W. W. Li, L. F. Wang and H. Q. Yu, Water Res., 2012, 46, 1817-1824.

57 W. W. Li and H. Q. Yu, Biotechnol. Adv., 2011, 29, 972-982.

58 J. J. Fornero, M. Rosenbaum and L. T. Angenent, Electroanalysis, 2010, 22, 832-843.

59 Y. Fan, S. K. Han and H. Liu, Energy Environ. Sci., 2012, 5, 8273-8280.

60 D. Pant, A. Singh, G. Van Bogaert, Y. A. Gallego, L. Diels and K. Vanbroekhoven, Renewable Sustainable Energy Rev., 2011, 15, 1305-1313.

61 US-EIA, Electric Power Monthly (with Data for April 2013), Washington, 2013.

62 P. Kuntke, K. M. Śmiech, H. Bruning, G. Zeeman, M. Saakes, T. H. J. A. Sleutels, H. V. M. Hamelers and C. J. N. Buisman, Water Res., 2012, 46, 2627-2636.

63 M. C. A. A. Van Eerten-Jansen, A. Ter Heijne, T. I. M. Grootscholten, K. J. J. Steinbusch, T. H. J. A. Sleutels, H. V. M. Hamelers and C. J. N. Buisman, ACS Sustainable Chem. Eng., 2013, 1, 513-518.

64 W. W. Li, G. P. Sheng, X. W. Liu and H. Q. Yu, Bioresour. Technol., 2011, 102, 244-252.

65 T. H. Pham, K. Rabaey, P. Aelterman, P. Clauwaert, L. De Schamphelaire, N. Boon and W. Verstraete, Eng. Life Sci., 2006, 6, 285-292.

66 X. Wang, Y. J. Feng and H. Lee, Water Sci. Technol., 2008, 57, 1117-1121.

67 Z. Ge, F. Zhang, J. Grimaud, J. Hurst and Z. He, Bioresour. Technol., 2013, 136, 509-514.

68 R. K. Goud and S. V. Mohan, Int. J. Hydrogen Energy, 2011, 36, 13753-13762.

69 S. T. Oh and A. D. Martin, Process Biochem., 2010, 45, 335345.

70 B. E. Logan, D. Call, S. Cheng, H. V. M. Hamelers, T. H. J. A. Sleutels, A. W. Jeremiasse and R. A. Rozendal, Environ. Sci. Technol., 2008, 42, 8630-8640.

71 G. C. Premier, J. R. Kim, J. Massanet-Nicolau, G. Kyazze, S. R. R. Esteves, B. K. V. Penumathsa, J. Rodríguez, J. Maddy, R. M. Dinsdale and A. J. Guwy, Renewable Energy, 2013, 49, 188-192.
72 I. Durruty, P. S. Bonanni, J. F. González and J. P. Busalmen, Bioresour. Technol., 2012, 105, 81-87.

73 Y. Sharma and B. Li, Int. J. Hydrogen Energy, 2010, 35, 37893797.

74 E. Lalaurette, S. Thammannagowda, A. Mohagheghi, P. C. Maness and B. E. Logan, Int. J. Hydrogen Energy, 2009, 34, 6201-6210.

75 S. V. Mohan, G. Mohanakrishna and P. Chiranjeevi, Bioresour. Technol., 2011, 102, 7036-7042.

76 B. Zhang, H. Zhao, S. Zhou, C. Shi, C. Wang and J. Ni, Bioresour. Technol., 2009, 100, 5687-5693.

77 O. Modin, IWA Leading Edge Technologies Conference, Bordeaux, France, 2013.

78 J. D. Vrieze, S. Gildemyn, J. Arends, N. Boon, W. Verstraete, T. Hennebel and K. Rabaey, Anaerobic Digestion, 13th World congress, 2013, http:/hdl.handle.net/1854/LU-4116201.

79 N. Gilbert, Nature, 2009, 461, 716-718.

80 W. Moerman, M. Carballa, A. Vandekerckhove, D. Derycke and W. Verstraete, Water Res., 2009, 43, 1887-1892.

81 T. Zhang, L. Ding, H. Ren and X. Xiong, Water Res., 2009, 43, 5209-5215.

82 X. Hao, C. Wang, M. C. M. van Loosdrecht and Y. Hu, Environ. Sci. Technol., 2013, 47, 4965-4966.

83 T. Michałowski and A. Pietrzyk, Talanta, 2006, 68, 594-601. 84 M. Maurer, W. Pronk and T. A. Larsen, Water Res., 2006, 40, 3151-3166.

85 G. L. Zang, G. P. Sheng, W. W. Li, Z. H. Tong, R. J. Zeng, C. Shi and H. Q. Yu, Phys. Chem. Chem. Phys., 2012, 14, 1978-1984.

86 O. Ichihashi and K. Hirooka, Bioresour. Technol., 2012, 114, 303-307.

87 D. P. B. T. B. Strik, H. V. M. Hamelers and C. J. N. Buisman, Environ. Sci. Technol., 2010, 44, 532-537.

88 T. Cai, S. Y. Park and Y. Li, Renewable Sustainable Energy Rev., 2013, 19, 360-369.

89 Z. He, J. Kan, F. Mansfeld, L. T. Angenent and K. H. Nealson, Environ. Sci. Technol., 2009, 43, 1648-1654.

90 J. G. G. Jonker and A. P. C. Faaij, Appl. Energy, 2013, 102, 461-475.

91 Y. Yuan, Q. Chen, S. Zhou, L. Zhuang and P. Hu, J. Hazard. Mater., 2011, 187, 591-595.

92 Y. Zhang, J. S. Noori and I. Angelidaki, Energy Environ. Sci., 2011, 4, 4340-4346.

93 L. Xiao, E. B. Young, J. A. Berges and Z. He, Environ. Sci. Technol., 2012, 46, 11459-11466.

94 S. Klimmek, H. J. Stan, A. Wilke, G. Bunke and R. Buchholz, Environ. Sci. Technol., 2001, 35, 4283-4288.

95 B. Van der Bruggen, Ind. Eng. Chem. Res., 2013, 52, 1033510341.

96 Y. P. Wang, X. W. Liu, W. W. Li, F. Li, Y. K. Wang, G. P. Sheng, R. J. Zeng and H. Q. Yu, Appl. Energy, 2012, 98, 230-235.

97 Y. K. Wang, G. P. Sheng, W. W. Li, Y. X. Huang, Y. Y. Yu, R. J. Zeng and H. Q. Yu, Environ. Sci. Technol., 2011, 45, 9256-9261.

98 Z. Ge, Q. Ping and Z. He, J. Chem. Technol. Biotechnol., 2013, 88, 1584-1590. 
99 Y. K. Wang, G. P. Sheng, B. J. Shi, W. W. Li and H. Q. Yu, Sci. Rep., 2013, 3, 1864.

100 US-EPA, Opportunities for and benefits of combined heat and power at wastewater treatment facilities, Washington DC, 2007.

101 I. Ieropoulos, J. Greenman and C. Melhuish, Phys. Chem. Chem. Phys., 2012, 14, 94-98.

102 L. Lu, D. Xing, B. Liu and N. Ren, Water Res., 2012, 46, 10151026.

103 G. Zhang, Q. Zhao, Y. Jiao, K. Wang, D. J. Lee and N. Ren, Water Res., 2012, 46, 43-52.

104 A. Borole, J. Mielenz, T. Vishnivetskaya and C. Hamilton, Biotechnol. Biofuels, 2009, 2, 7-20.

105 Y. Zhang, E. Desmidt, A. Van Looveren, L. Pinoy, B. Meesschaert and B. Van der Bruggen, Environ. Sci. Technol., 2013, 47, 5888-5895.

106 Z. Shu, J. R. Bolton, M. Belosevic and M. Gamal El Din, Water Res., 2013, 47, 2881-2889.

107 B. E. Logan and K. Rabaey, Science, 2012, 337, 686-690.

108 A. P. Borole, Biofuels, Bioprod. Biorefin., 2011, 5, 28-36.

109 B. C. H. Steele and A. Heinzel, Nature, 2001, 414, 345-352.

110 P. Aelterman, K. Rabaey, H. T. Pham, N. Boon and W. Verstraete, Environ. Sci. Technol., 2006, 40, 3388-3394.

111 D. Kim, J. An, B. Kim, J. K. Jang, B. H. Kim and I. S. Chang, ChemSusChem, 2012, 5, 1086-1091.

112 Y. Kim, M. C. Hatzell, A. J. Hutchinson and B. E. Logan, Energy Environ. Sci., 2011, 4, 4662-4667.

113 P. Ledezma, J. Greenman and I. Ieropoulos, Bioresour. Technol., 2013, 134, 158-165.

114 L. Zhuang and S. Zhou, Electrochem. Commun., 2009, 11, 937-940.

115 X. Wang, S. Cheng, Y. Feng, M. D. Merrill, T. Saito and B. E. Logan, Environ. Sci. Technol., 2009, 43, 6870-6874.

116 B. E. Logan, S. A. Cheng, V. Watson and G. Estadt, Environ. Sci. Technol., 2007, 41, 3341-3346.

117 X. Y. Zhang, S. A. Cheng, P. Liang, X. Huang and B. E. Logan, Bioresour. Technol., 2011, 102, 372-375.

118 L. Malaeb, K. P. Katuri, B. E. Logan, H. Maab, S. P. Nunes and P. E. Saikaly, Environ. Sci. Technol., 2013, 47, 1182111828.

119 F. Zhang, K. S. Brastad and Z. He, Environ. Sci. Technol., 2011, 45, 6690-6696.

120 X. Zhang, S. Cheng, X. Wang, X. Huang and B. E. Logan, Environ. Sci. Technol., 2009, 43, 8456-8461.

121 Y. Qiao, S. J. Bao and C. M. Li, Energy Environ. Sci., 2010, 3, 544-553.

122 Y. Yuan, J. Ahmed, L. Zhou, B. Zhao and S. Kim, Biosens. Bioelectron., 2011, 27, 106-112.

123 X. Xie, G. Yu, N. Liu, Z. Bao, C. S. Criddle and Y. Cui, Energy Environ. Sci., 2012, 5, 6862-6866.

124 N. S. Malvankar, M. Vargas, K. P. Nevin, A. E. Franks, C. Leang, B.-C. Kim, K. Inoue, T. Mester, S. F. Covalla, J. P. Johnson, V. M. Rotello, M. T. Tuominen and D. R. Lovley, Nat. Nanotechnol., 2011, 6, 573-579.

125 N. S. Malvankar, M. T. Tuominen and D. R. Lovley, Energy Environ. Sci., 2012, 5, 5790-5797.

126 D. R. Lovley, Annu. Rev. Microbiol., 2012, 66, 391-409.
127 N. S. Malvankar and D. R. Lovley, ChemSusChem, 2012, 5, 1039-1046.

128 A. Meehan, H. Gao and Z. Lewandowski, IEEE Trans. Power Electron., 2011, 26, 176-181.

129 C. Donovan, A. Dewan, H. Peng, D. Heo and H. Beyenal, J. Power Sources, 2011, 196, 1171-1177.

130 J.-D. Park and Z. Ren, J. Power Sources, 2012, 208, 322-327.

131 A. Deeke, T. H. J. A. Sleutels, H. V. M. Hamelers and C. J. N. Buisman, Environ. Sci. Technol., 2012, 46, 35543560 .

132 Z. Lv, D. Xie, F. Li, Y. Hu, C. Wei and C. Feng, J. Power Sources, 2014, 246, 642-649.

133 A. Esteve-Núñez, J. Sosnik, P. Visconti and D. R. Lovley, Environ. Microbiol., 2008, 10, 497-505.

134 D. R. Bond, S. M. Strycharz-Glaven, L. M. Tender and C. I. Torres, ChemSusChem, 2012, 5, 1099-1105.

135 N. S. Malvankar, T. Mester, M. T. Tuominen and D. R. Lovley, ChemPhysChem, 2012, 13, 463-468.

136 D. R. Lovley, Curr. Opin. Biotechnol., 2008, 19, 564-571.

137 X. Xia, J. C. Tokash, F. Zhang, P. Liang, X. Huang and B. E. Logan, Environ. Sci. Technol., 2013, 47, 2085-2091.

138 S. M. Strycharz-Glaven, R. M. Snider, A. Guiseppi-Elie and L. M. Tender, Energy Environ. Sci., 2011, 4, 4366-4379.

139 T. S. Magnuson, J. Bacteriol., 2011, 193, 1021-1022.

140 N. S. Malvankar, M. T. Tuominen and D. R. Lovley, Energy Environ. Sci., 2012, 5, 6247-6249.

141 S. M. Strycharz-Glaven and L. M. Tender, Energy Environ. Sci., 2012, 5, 6250-6255.

142 G. D. Schrott, P. S. Bonanni, L. Robuschi, A. Esteve-Nuñez and J. P. Busalmen, Electrochim. Acta, 2011, 56, 1079110795.

143 J. P. Veazey, G. Reguera and S. H. Tessmer, Phys. Rev. E: Stat., Nonlinear, Soft Matter Phys., 2011, 84, 060901.

144 R. S. Hartshorne, C. L. Reardon, D. Ross, J. Nuester, T. A. Clarke, A. J. Gates, P. C. Mills, J. K. Fredrickson, J. M. Zachara, L. Shi, A. S. Beliaev, M. J. Marshall, M. Tien, S. Brantley, J. N. Butt and D. J. Richardson, Proc. Natl. Acad. Sci. U. S. A., 2009, 106, 22169-22174.

145 A. Jain, X. Zhang, G. Pastorella, J. O. Connolly, N. Barry, R. Woolley, S. Krishnamurthy and E. Marsili, Bioelectrochemistry, 2012, 87, 28-32.

146 N. F. Polizzi, S. S. Skourtis and D. N. Beratan, Faraday Discuss., 2012, 155, 43-62.

147 L. A. Fitzgerald, E. R. Petersen, R. I. Ray, B. J. Little, C. J. Cooper, E. C. Howard, B. R. Ringeisen and J. C. Biffinger, Process Biochem., 2012, 47, 170-174.

148 A. Okamoto, K. Hashimoto and R. Nakamura, Bioelectrochemistry, 2012, 85, 61-65.

149 A. Kouzuma, X. Y. Meng, N. Kimura, K. Hashimoto and K. Watanabe, Appl. Environ. Microbiol., 2010, 76, 4151-4157.

150 J. B. Rollefson, C. S. Stephen, M. Tien and D. R. Bond, J. Bacteriol., 2011, 193, 1023-1033.

151 Z. M. Summers, H. E. Fogarty, C. Leang, A. E. Franks, N. S. Malvankar and D. R. Lovley, Science, 2010, 330, 1413-1415.

152 C. Pfeffer, S. Larsen, J. Song, M. Dong, F. Besenbacher, R. L. Meyer, K. U. Kjeldsen, L. Schreiber, Y. A. Gorby, 
M. Y. El-Naggar, K. M. Leung, A. Schramm, N. RisgaardPetersen and L. P. Nielsen, Nature, 2012, 491, 218221.

153 S. J. Yuan, W. W. Li, Y. Y. Cheng, H. He, J.-J. Chen, Z. H. Tong, Z. Q. Lin, Z. Feng, G. P. Sheng and H. Q. Yu, Nat. Protoc., 2014, 9, 112-119.

154 S. M. Strycharz, R. H. Glaven, M. V. Coppi, S. M. Gannon, L. A. Perpetua, A. Liu, K. P. Nevin and D. R. Lovley, Bioelectrochemistry, 2011, 80, 142-150.

155 M. Rosenbaum, F. Aulenta, M. Villano and L. T. Angenent, Bioresour. Technol., 2011, 102, 324-333.

156 A. E. Franks, R. H. Glaven and D. R. Lovley, ChemSusChem, 2012, 5, 1092-1098.

157 B. Virdis, F. Harnisch, D. J. Batstone, K. Rabaey and B. C. Donose, Energy Environ. Sci., 2012, 5, 7017-7024.

158 A. Kuzume, U. Zhumaev, J. Li, Y. Fu, M. Füeg, A. EsteveNuñez and T. Wandlowski, Electrochim. Acta, 2013, 112, 933-942.

159 Y. C. Yong, Y. Y. Yu, C. M. Li, J. J. Zhong and H. Song, Biosens. Bioelectron., 2011, 30, 87-92.

160 L. Alfonta, Electroanalysis, 2010, 22, 822-831.

161 J. Lin and D. N. Beratan, J. Phys. Chem. B, 2005, 109, 75297534.

162 X. W. Liu, X. F. Sun, J. J. Chen, Y. X. Huang, J. F. Xie, W. W. Li, G. P. Sheng, Y. Y. Zhang, F. Zhao, R. Lu and H. Q. Yu, Sci. Rep., 2013, 3, 1616.

163 L. Lu, D. Xing and N. Ren, Water Res., 2012, 46, 2425-2434. 164 P. D. Kiely, J. M. Regan and B. E. Logan, Curr. Opin. Biotechnol., 2011, 22, 378-385.

165 R. J. Weld and R. Singh, Bioresour. Technol., 2011, 102, 842847.
166 P. D. Kiely, G. Rader, J. M. Regan and B. E. Logan, Bioresour. Technol., 2011, 102, 361-366.

167 J. N. Roy, H. R. Luckarift, S. R. Sizemore, K. E. Farrington, C. Lau, G. R. Johnson and P. Atanassov, Enzyme Microb. Technol., 2013, 53, 123-127.

168 J. Zhang, E. Zhang, K. Scott and J. G. Burgess, Environ. Sci. Technol., 2012, 46, 2984-2992.

169 M. Picot, L. Lapinsonnière, M. Rothballer and F. Barrière, Biosens. Bioelectron., 2011, 28, 181-188.

170 A. Venkataraman, M. Rosenbaum, J. B. A. Arends, R. Halitschke and L. T. Angenent, s, 2010, 12, 459-462.

171 J. D. Shrout and R. Nerenberg, Environ. Sci. Technol., 2012, 46, 1995-2005.

172 D. R. Lovley, Energy Environ. Sci., 2011, 4, 4896-4906.

173 T. K. Wood, S. H. Hong and Q. Ma, Trends Biotechnol., 2010, 29, 87-94.

174 A. Kaur, J. R. Kim, I. Michie, R. M. Dinsdale, A. J. Guwy and G. C. Premier, Biosens. Bioelectron., 2013, 47, 50-55.

175 R. C. Wagner, D. F. Call and B. E. Logan, Environ. Sci. Technol., 2010, 44, 6036-6041.

176 L. Woodward, M. Perrier, B. Srinivasan, R. P. Pinto and B. Tartakovsky, AIChE J., 2010, 56, 2742-2750.

177 R. S. Renslow, J. T. Babauta, P. D. Majors and H. Beyenal, Energy Environ. Sci., 2013, 6, 595-607.

178 F. Dong, Q. B. Zhao, W. W. Li, G. P. Sheng, J. B. Zhao, Y. Tang, H. Q. Yu, K. Kubota, Y. Y. Li and H. Harada, Environ. Sci. Technol., 2011, 45, 9093-9100.

179 H. C. Shi, B. D. Song, F. Long, X. H. Zhou, M. He, Q. Lv and H. Y. Yang, Environ. Sci. Technol., 2013, 47, 4434-4441.

180 R. Lu, G. Sheng, W. Li, H. Yu, Y. Raichlin, A. Katzir and B. Mizaikoff, Angew. Chem., Int. Ed., 2013, 52, 2265-2268. 